\title{
Treatment of shoulder pain in spastic hemiplegia by reducing spasticity of the subscapular muscle: a randomised, double blind, placebo controlled study of botulinum toxin A
}

\author{
Alain P Yelnik, Florence M Colle, Isabelle V Bonan, Eric Vicaut
}

See Editorial Commentary, p 789

J Neurol Neurosurg Psychiatry 2007;78:845-848. doi: 10.1136/jnnp.2006.103341

See end of article for authors' affiliations

Correspondence to:

Dr Alain P Yelnik, AP-HP,

GH Lariboisière-F Widal, Physical Medicine and

Rehabilitation Department, 200 rue du Faubourg Saint Denis, 75010 Paris, France; alain.yelnik@|rb.aphp.fr

Received 7 August 2006 Revised 11 October 2006 Accepted 12 October 2006 Published Online First 6 November 2006
Objective: This randomised, double blind, placebo controlled, two parallel group study was conducted to assess the beneficial effect of injection of botulinum toxin A (Dysport) into the subscapularis muscle on shoulder pain in stroke patients with spastic hemiplegia.

Methods: A single dose of botulinum toxin A (500 Speywood units) or placebo was injected into the subcapularis muscle. Pain was assessed using a 10 point verbal scale. Subscapularis spasticity was assessed by the change in passive shoulder lateral rotation and abduction. Upper limb spasticity was assessed using the Modified Ashworth Scale for shoulder medial rotators, and elbow, wrist and finger flexors. Assessments were carried out at baseline and at weeks 1,2 and 4.

Results: Twenty patients (10 patients per group), 11 with ischaemic stroke and 9 with haemorrhagic stroke, completed the study. Pain improvement with botulinum toxin A was observed from week 1; score difference from baseline at week 4 was 4 points versus 1 point with placebo $(p=0.025)$. Lateral rotation was also improved, with a statistically significant difference compared with placebo at week $2(p=0.05)$ and week 4 $(p=0.018)$. A general improvement in upper limb spasticity was observed; it was significant for finger flexors at week $4(p=0.025)$.

Conclusions: Subscapularis injection of botulinum toxin A appears to be of value in the management of shoulder pain in spastic hemiplegic patients. The results confirm the role of spasticity in post-stroke shoulder pain.
$\mathrm{P}$ ain and spastic shoulder are frequent in hemiplegia following a stroke. Shoulder pain is a major problem for these patients, interfering with physiotherapy, sleep and daily activities. It is usually due to local causes: algoneurodystrophy (shoulder-hand syndrome), capsulitis, glenohumeral subluxation and also spasticity because of the prolonged muscular contracture and possible tendinopathies. ${ }^{1-4}$ These causes can be associated, especially spasticity and algoneurodystrophy in severe hemiplegia, and patients exhibit the typical arm posture: adduction and medial rotation of the shoulder, and flexion of the elbow, wrist and finger.

Different approaches are used for treatment of pain in such patients, depending on the mechanism involved. Oral medications for pain, as those for spasticity, are usually ineffective or insufficient. Treatment of algoneurodystrophy and capsulitis mainly consists of corticosteroids, systemic treatment being more effective than local administration. ${ }^{35}$ To treat spasticity or its consequences, transection of the subscapularis tendon ${ }^{67}$ or subcapularis nerve block $^{8}{ }^{9}$ has been reported, but these treatments are not in common use. Botulinum toxin A has been shown to be effective in reducing spasticity and increasing the passive range of motion of the spastic upper limb in hemiplegic patients ${ }^{10-14}$ with a real functional benefit. ${ }^{15}$ The effect of botulinum toxin A on shoulder pain after a stroke has not been systematically studied. However, improvement of pain by the toxin has been reported in a placebo controlled study, although pain was not the main objective of the study. ${ }^{15} \mathrm{~A}$ beneficial effect has also been observed in an open study. ${ }^{16}$ Other controlled studies in which upper limb pain was assessed failed to show a significant reduction in pain. ${ }^{10-12}$

No specific treatment of the spastic shoulder muscles has been studied. Suprasupinator and infrasupinator muscles are not involved in painful contracted shoulder, ${ }^{17}$ and among the muscles implicated in medial rotation, the subscapularis and pectoralis muscles undoubtedly play a major role, ${ }^{18}$ with apparent pre-eminence of the subscapularis muscle. ${ }^{19}$ In a recent study of three cases, injection of botulinum toxin A into the subscapularis muscle was shown to reduce pain and improve the passive range of motion. ${ }^{18}$

Based on these observations, we formed the hypothesis that shoulder pain occurring in patients with spastic hemiplegia, even with limited range of motion compatible with capsulitis, can be relieved by reducing the spasticity of the main medial rotator muscle (ie, the subscapularis muscle). Therefore, we conducted the present study to further assess the beneficial effect of injection of botulinum toxin A (Dysport) into the subscapularis muscle on shoulder pain. An improvement in the passive range of motion was expected as a parameter of the efficacy of botulinum toxin on spasticity and as a possible secondary benefit.

\section{PATIENTS AND METHOD}

\section{Study design and patients}

The study was conducted according to a randomised, double blind, placebo controlled, parallel group design in hemiplegic patients of either sex presenting with upper limb spasticity related to cerebral stroke. Patients were included whatever the post-stroke stage. Spasticity was characterised by a score of at least $1+$ on the Modified Ashworth Scale (MAS) ${ }^{20}$ for the medial rotators and elbow flexors, with limited range of passive motion of the shoulder: external rotation $10^{\circ}$ or $<30^{\circ}$ related to the opposite side. Patients gave written informed consent before entering the study. The following criteria excluded patients from selection: previous traumatic or neurological

Abbreviation: MAS, Modified Ashworth Scale 
disease of the hemiplegic shoulder; retraction of at least one muscle of the elbow, wrist or fingers in the hemiplegic upper limb; previous treatment with botulinum toxin A or alcohol in the subscapularis muscle of the hemiplegic shoulder; neuromuscular disease such as myasthenia gravis; pregnant or lactating female patients; other common exclusion criteria for clinical trials. Concomitant treatment with drugs affecting muscle tone was allowed when initiated at least 2 weeks before inclusion, and without changes in the doses; it was then continued through the follow-up post-injection period without any change. Five patients (one in the toxin group, four in the placebo group) were previously treated with botulinum toxin A for upper (never in the shoulder muscles) or lower limb spasticity, always with Dysport, and at least 3 months ago. The study was conducted in accordance with the guidelines of the Declaration of Helsinki and prevailing amendments, and was formally approved by the Ethics Committee of Saint-Louis Hospital (Paris, France).

\section{Treatment}

Treatment was allocated by computerised randomisation. Patients were seated on the edge of their bed, with the arm against the trunk, the shoulder being slightly pushed backward by an assistant to produce as much winging of the scapula as possible. An $0.8 \mathrm{~mm}$ diameter, $100 \mathrm{~mm}$ needle coated with Teflon, except for the tip, was inserted in the medial scapular border, slightly below the level of the spine of the scapula, along its anterior face, pointing at the acromion, as previously described. ${ }^{18}$ Before the intramuscular injection, the needle was used as a stimulation electrode to detect the motor point where minimal stimulation induces maximum internal rotation, and then botulinum toxin A (Dysport, 500 Speywood units) or placebo (all constituents of Dysport solvent) was injected while pulling back the needle by $1-2 \mathrm{~cm}$. In addition, all patients received after treatment, on weekdays-non-standardised physical therapy for stretching, spasticity inhibition and increasing active motion when possible.

\section{Methods of assessment}

Pain was assessed using a 10 point verbal scale or, for aphasic patients only (one in the placebo group, three in the toxin group), a visual analogue scale. Subscapularis muscle spasticity was assessed, with the patient sitting, by a range of motion inducing a strong resistance after slow stretching in passive

Table 1 Demographic characteristics and disease history

\begin{tabular}{|c|c|c|}
\hline & $\begin{array}{l}\text { Placebo } \\
(n=10)\end{array}$ & $\begin{array}{l}\text { Dysport } \\
(n=10)\end{array}$ \\
\hline Age $(y)^{*}$ & $55.2(8.3)$ & $53.0(4.6)$ \\
\hline \multicolumn{3}{|l|}{$\operatorname{Sex}(n(\%))$} \\
\hline Female $†$ & $2(20 \%)$ & $3(30 \%)$ \\
\hline Male & $8(80 \%)$ & $7(70 \%)$ \\
\hline \multicolumn{3}{|l|}{ Aetiology } \\
\hline Central stroke (n/N (\%)) & $10 / 10$ (100\%) & $10 / 10(100 \%)$ \\
\hline Haemorrhage (n/N (\%)) & $6 / 10(60 \%)$ & $3 / 10(30 \%)$ \\
\hline Capsulothalamic (n/N) & $5 / 6$ & $2 / 3$ \\
\hline Cortical/subcortical (n/N) & $1 / 6$ & $1 / 3$ \\
\hline Ischaemia (n/N (\%)) & $4 / 10(40 \%)$ & $7 / 10(70 \%)$ \\
\hline Middle cerebral artery $(n / N)$ & $4 / 4$ & $7 / 7$ \\
\hline Anterior cerebral artery $(\mathrm{n} / \mathrm{N})$ & $0 / 4$ & $1 / 7$ \\
\hline \multicolumn{3}{|l|}{ Location of cerebral lesion (n/N (\%)) } \\
\hline Right side & $6 / 10(60 \%)$ & $4 / 10(40 \%)$ \\
\hline Left side & $4 / 10(40 \%)$ & $6 / 10(60 \%)$ \\
\hline $\begin{array}{l}\text { Time between lesion and Dysport } \\
\text { treatment (days) }\end{array}$ & $794(1050)$ & 224 (187) \\
\hline $\begin{array}{l}\text { *Values are mean (SD). } \\
\text { tOne female patient with childbearin } \\
\text { two in the Dysport group. }\end{array}$ & tivi & hearoun and \\
\hline
\end{tabular}

lateral rotation and abduction measured in degrees. Assessment of the spasticity of the whole upper limb was carried out, with the patient sitting, using the MAS for shoulder medial rotators, elbow flexors, wrist flexors and fingers flexors. These assessments were carried out at baseline and at weeks 1, 2 and 4 . In addition to the assessments of pain, consumption of analgesics at baseline and at week 4 was recorded.

The change from baseline in pain associated with spasticity, as assessed by the patient, was calculated at each visit. The change in consumption of analgesics between baseline and week 4 was coded by the investigator as increased (increasing the dosage or changing to another analgesic), no change or decreased. The change in shoulder range of motion was assessed by the change from baseline in lateral rotation and in abduction values at week 1, week 2 and week 4 visits. Changes from baseline in MAS scores for each muscle group were calculated at each visit.

\section{Statistical analyses}

As the statistical distributions of the pain and range of motion parameters were a priori not Gaussian, non-parametric tests were used. As calculated according to the method of Noether, ${ }^{21}$ the population required to detect a difference in the distribution of values between the two groups with an $80 \%$ power and a two sided 5\% confidence level was 24 patients (ie, 12 per group). Characteristics of the patients in the two groups at baseline were compared using exact 95\% confidence intervals (CI). Covariance analyses adjusted on values at baseline were used to compare pain reduction and change in range of motion between the two groups at each visit. ${ }^{22} \mathrm{~A} \chi^{2}$ test was used for comparisons of differences in MAS scores.

\section{RESULTS}

\section{Patient characteristics at baseline}

Twenty patients, 10 in each group, were recruited and completed the study. This population fell short of the planned 24 patients because of the difficulty in recruitment, as explained in the discussion. The characteristics of the patients are shown in table 1. As determined from exact 95\% CI, there were no statistically significant differences between groups for age or sex. The same was true for all parameters of disease history and for the time elapsed since cerebral stroke.

\section{Clinical efficacy}

Median pain scores and quartiles in the two treatment groups at baseline and at the post-treatment time points are summarised in table 2 . There was no statistically significant difference in baseline pain scores between the two groups. As shown by the mean changes from baseline (fig 1), pain improvement was observed throughout the observation period following Dysport, while minimal post-treatment changes were observed after placebo administration. Pain improvement appeared as early as week 1 and was significantly different from baseline (4 points vs 1 point in the placebo group; $p=0.025)$ at week 4. Consumption of analgesics in the Dysport group was unchanged in $5 / 6$ patients and increased in only $1 / 6$ patients. In the placebo group, it was unchanged in $2 / 5$ patients and increased in $3 / 5$ patients. However, the difference in consumption between the two groups was not statistically significant.

Values for lateral rotation and abduction of the hemiplegic spastic shoulder are summarised by time point in table 2 . Median baseline values for the two parameters were similar at baseline and showed wide individual variations. In the Dysport group, the amplitude of external rotation was improved as early as week 1 , showing a change from a median of $0^{\circ}$ at baseline to $10^{\circ}$. Change from baseline in external rotation became 
Table 2 Median pain scores and passive range of motion, as assessed by patients at baseline and at the post-treatment time points

\begin{tabular}{|c|c|c|}
\hline & Placebo $(n=10)$ & Dysport $(n=10)$ \\
\hline \multicolumn{3}{|l|}{ Baseline } \\
\hline Pain & $5.5[4$ to 8$]$ & $7.5[5$ to 8$]$ \\
\hline Lateral rotation & $0.0[-10$ to 5$]$ & $0[-10$ to 0$]$ \\
\hline Abduction & $65.0[50$ to 70$]$ & 70.0 [55 to 75$]$ \\
\hline \multicolumn{3}{|l|}{ Week 1} \\
\hline Pain & $4[3$ to 6$]$ & $3[1$ to 6$]$ \\
\hline Lateral rotation & $0.0[-20$ to 30$]$ & $10.0[5$ to 20$]$ \\
\hline Abduction & $72.5[60$ to 80$]$ & $75.0[60$ to 80$]$ \\
\hline \multicolumn{3}{|l|}{ Week 2} \\
\hline Pain & 4 [3 to 5$]$ & 2.5 [1 to 3$]$ \\
\hline Lateral rotation & $0.0[-10$ to 10$]$ & 10.0 [0 to 15] \\
\hline Abduction & $70.0[60$ to 80$]$ & $70.0[70$ to 80$]$ \\
\hline \multicolumn{3}{|l|}{ Week 4} \\
\hline Pain & $4[4$ to 7$]$ & 1.5 [1 to 3$]$ \\
\hline Lateral rotation & $-2.5[-15$ to 10$]$ & 12.5 [0 to 20 ] \\
\hline Abduction & $70.0[60$ to 85$]$ & 72.5 [70 to 80$]$ \\
\hline
\end{tabular}

statistically significant compared with placebo at week 2 $(p=0.05)$ and even more so at week $4 \quad(p=0.018)$. Improvement in abduction was less marked and was not statistically significant compared with placebo (table 3).

Compared with baseline MAS scores, there was a general decrease in the spasticity of the upper limb muscles, especially the elbow flexors, wrist flexors and finger flexors. However, differences in changes from baseline between the groups were statistically significant only for finger flexors at week 4: MAS score decreased by 2 points in $2 / 10$ patients, by 1 point in $5 / 10$ patients and did not change in 3/10 patients, whereas in the placebo group no change was observed in $8 / 10$ patients and an increase of 1 point was observed in $1 / 10$ patients $(p=0.025)$.

As time elapsed after stroke was different between the groups (although this was not significant), a post hoc analysis was conducted to confirm that the observed effect in the Dysport group was not caused by previous subscapularis muscle treatment in that group. However, it appeared that the longer the time after stroke, the better was the effect. Thus taking into account the time elapsed since the cerebral lesion, covariance analysis $^{22}$ showed stronger statistical results, with pain being significantly reduced at week $2(\mathrm{p}=0.042)$ and at week 4 $(p=0.007)$, and improvement in lateral rotation being significant at week $2(\mathrm{p}=0.019)$ and at week $4(\mathrm{p}=0.002)$.

\section{Tolerance}

During the 4 week study period, three patients of the Dysport group experienced treatment unrelated adverse events: moderate orchitis, mild influenza and vasovagal syncope. In the placebo group, one patient experienced severe injection pain

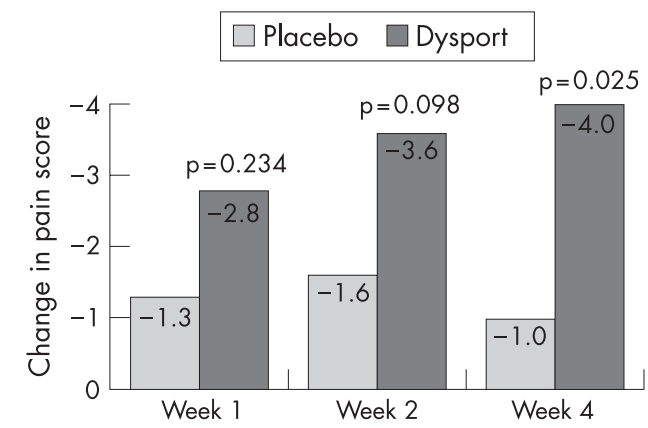

Figure 1 Median change from baseline in pain scores at the posttreatment time points in the placebo and Dysport groups.

and pain thereafter, probably related to the injection process rather than to the placebo itself; another patient experienced somnolence.

\section{DISCUSSION}

Twenty patients were included in this randomised, double blind, placebo controlled study with the objective of assessing the efficacy of a single injection of botulinum toxin A into the subscapularis muscle to reduce pain associated with shoulder spasticity after stroke. The main finding was improvement in pain. A clinically significant improvement in passive lateral rotation was concurrently observed, resulting from a decrease in local spasticity. External rotation improved markedly, more than abduction, which is not surprising because the subscapularis muscle is a strong internal rotator with limited impact on abduction. At the same time as the improvement in shoulder pain and range of motion, spasticity of the upper limb muscles appeared to be reduced. The improvement was statistically significant for the finger flexors. This confirms clinical experience, suggesting that part of the spasticity of these muscles remote from the injection point is related to shoulder pain. Another interesting point is that, contrary to what would have been expected, the longer the time after stroke, the better were the results. This suggests that algoneurodystrophy and capsulitis, often associated with spasticity in severe hemiplegia but for which botulinum toxin is not a treatment, mainly occurred during the first months after the stroke, whereas pain remaining for longer was primarily caused by spasticity and thus could be treated by relieving spasticity with botulinum toxin A.

The population size may have hindered the evaluation of the efficacy of botulinum toxin A on the range of motion of the spastic shoulder. Sample size estimation was 24 patients based on an expected large effect size. However, the difficulty in recruitment limited the study population to 20 . This difficulty was mainly because of the impossibility, in the time frame of

Table 3 Changes from baseline in hemiplegic spastic lateral rotation and abduction at the post-treatment time points

\begin{tabular}{lllll}
\hline \multirow{2}{*}{$\begin{array}{llll}\text { Shoulder motion } \\
\text { parameter }\end{array}$} & $\begin{array}{l}\text { Time of } \\
\text { assessment }\end{array}$ & \multicolumn{2}{l}{ Difference from baseline* } & \\
\cline { 2 - 4 } & Placebo & Dysport & p Value† \\
\hline Lateral rotation & Week 1 & $7.5(-5 ; 35)$ & $10.0(0 ; 40)$ & 0.131 \\
& Week 2 & $5.0(-20 ; 25)$ & $10.0(0 ; 60)$ & 0.05 \\
& Week 4 & $7.5(-20 ; 15)$ & $15.0(-15 ; 45)$ & 0.018 \\
Abduction & Week 1 & $10.0(-10 ; 35)$ & $5.0(0 ; 15)$ & 0.588 \\
& Week 2 & $2.5(-5 ; 35)$ & $7.5(0 ; 15)$ & 0.654 \\
& Week 4 & $2.5(-5 ; 35)$ & $7.5(-5 ; 20)$ & 0.894 \\
\hline
\end{tabular}

*Values are median (min; max) in degrees.

†Non-parametric model adjusted to value at baseline. 
this study, to concurrently treat other spastic muscle groups, which was difficult to accept, as spasticity in hemiplegic patients is not usually limited to the shoulder. Despite the reduced population, the results retained a sufficient statistical power.

The injection technique used was derived from that described for subscapular motor point block $^{8}$ but patient position was modified, as previously proposed. ${ }^{18}$ In our experience, keeping the patient seated makes the injection easier, as the scapula is maintained separated from the thorax by an assistant standing in front of the patient and pushing back the shoulder. In this position, the subscapularis muscle is usually not difficult to find. The best response to electrostimulation is usually obtained between 6 and $8 \mathrm{~cm}$ from the edge of the scapula. Nevertheless, in the present study, one patient (on placebo) suffered severe pain on injection because of the conflict of the needle and the anterior face of the scapula.

The reduction in pain by subscapular injection of botulinum toxin $\mathrm{A}$, with a concurrent improvement in shoulder range of motion observed in the present study, confirms the role of spasticity in hemiplegic shoulder pain. Currently, the treatment of hemiplegic shoulder pain focuses on algoneurodystrophy or capsulitis, often considered the main causes of pain. Yet, the contribution of spasticity deserves to be systematically considered because pain is more frequent in spastic patients than in flaccid patients. ${ }^{14}$ The possible efficacy of triamcinolone injection to relieve pain supposedly related to capsulitis in hemiplegic patients with a limited range of motion, as reported by some authors, ${ }^{23}$ has not been confirmed in a randomised, placebo controlled trial. ${ }^{5}$ Moreover, our results confirm that the limited range of passive lateral rotation and limited abduction, the usual criteria of capsulitis, can be due to spasticity in hemiplegic patients. Surprisingly, the effect of botulinum toxin A in relieving pain of the shoulder or the upper limb after stroke has not been systematically studied. The present study is the first to focus specifically on pain related to spasticity in poststroke hemiplegic patients, with specific treatment of the shoulder muscles. Our results confirm those observed in three previously published cases. ${ }^{18}$

\section{CONCLUSION}

Injection of botulinum toxin A (Dysport) into the subscapularis muscle appears to be of value in the management of shoulder pain in spastic hemiplegic patients. The results confirm the role of spasticity in post-stroke shoulder pain, which deserves to be systematically considered. However, injection of the subscapularis muscle only, as conducted here for medical research purposes, cannot be recommended. In the management of spasticity in hemiplegic stroke patients, treatment of all of the muscles involved has to be discussed while keeping in mind that, among them, the subscapularis muscle can be injected with success.

\section{Authors' affiliations}

A P Yelnik, F M Colle, I V Bonan, Physical Medicine and Rehabilitation Department, AP-HP, GH Lariboisière-F Widal, University Paris 7, France
E Vicaut, Clinical Research Unit, Lariboisière-Saint Louis, University Paris 7, France

Competing interests: In the past 5 years, AY and FC have been reimbursed by Ipsen Pharma, the manufacturer of Dysport, for attending several conferences.

\section{REFERENCES}

1 Daviet JC, Preux PM, Salle JY, et al. Clinical factors in the prognosis of complex regional pain syndrome type I after stroke: A prospective stuffy. Am J Phys Med Rehabil 2002;81:34-9.

2 Bohannon RW, Larkin PA, Smith MB, et al. Shoulder pain in hemiplegia: statistical relationship with five variables. Arch Phys Med Rehabil 1986;67:514-16

3 Geurts AC, Visschers BA, van Limbeek J, et al. Systematic review of aetiology and treatment of post-stroke hand oedema and shoulder-hand syndrome. Scand J Rehabil Med 2000;32:4-10.

4 Van Ouwenaller C, Laplace PM, Chantraine A. Painful shoulder in hemiplegia. Arch Phys Med Rehabil 1986;67:23-6.

5 Snels IA, Beckerman H, Twisk JW, et al. Effect of triamcinolone acetonide injections on hemiplegic shoulder pain: A randomized clinical trial. Stroke 2000;31:2396-401.

6 Caldwell CB, Wilson DJ, Braun RM. Evaluation and treatment of the upper extremity in the hemiplegic stroke patient. Clin Orthop Relat Res 1969;63:69-93.

7 Braun RM, West F, Mooney V, et al. Surgical treatment of the painful shoulder contracture in the stroke patient. J Bone Joint Surg Am 1971;53:1307-12.

8 Chironna RL, Hecht JS. Subscapularis motor point block for the painful hemiplegic shoulder. Arch Phys Med Rehabil 1990;71:428-9.

9 Hecht JS. Subscapular nerve block in the painful hemiplegic shoulder. Arch Phys Med Rehabil 1992;73:1036-9.

10 Bakheit AM, Thilmann AF, Ward AB, et al. A randomized, double-blind, placebo-controlled, dose-ranging study to compare the efficacy and safety of three doses of botulinum toxin type A (Dysport) with placebo in upper limb spasticity after stroke. Stroke 2000;31:2402-6.

11 Bakheit AM, Pittock S, Moore AP, et al. A randomized, double-blind, placebocontrolled study of the efficacy and safety of botulinum toxin type $A$ in upper limb spasticity in patients with stroke. Eur J Neurol 2001;8:559-65.

12 Bhakta BB, Cozens JA, Chamberlain MA, et al. Impact of botulinum toxin type A on disability and carer burden due to arm spasticity after stroke: a randomized double-blind placebo-controlled trial. J Neurol Neurosurg Psychiatry 2000;69:217-21.

13 Simpson DM, Alexander DN, O'Brien CF, et al. Botulinum toxin type $A$ in the treatment of upper extremity spasticity: a randomized, double-blind, placebocontrolled trial. Neurology 1996;46:1306-10.

14 Smith SJ, Ellis E, White S, et al. A double-blind placebo-controlled study of botulinum toxin in upper limb spasticity after stroke or head injury. Clin Rehabil 2000;14:5-13.

15 Brashear A, Gordon MF, Elovic E, et al. Intramuscular injection of botulinum toxin for the treatment of wrist and finger spasticity after a stroke. N Engl J Med 2002;347:395-400.

16 Wang HC, Hsieh LF, Chi WC, et al. Effect of intramuscular botulinum toxin injection on upper limb spasticity in stroke patients. Am J Phys Med Rehabil 2002;81:272-8.

17 Lee KH, Khunadorn F. Painful shoulder in hemiplegic patients: a study of the suprascapular nerve. Arch Phys Med Rehabil 1986;67:818-20.

18 Yelnik AP, Colle FM, Bonan IV. Treatment of pain and limited movement of the shoulder in hemiplegic patients with botulinum toxin $A$ in the subscapular muscle. Eur Neurol 2003;50:91-3.

19 Chang YW, Hughes RE, Su FC, et al. Prediction of muscle force involved in shoulder internal rotation. J Shoulder Elbow Surg 2000;9:188-95.

20 Bohannon RW, Smith MB. Interrater reliability of a modified Ashworth scale of muscle spasticity. Phys Ther 1987;67:206-7.

21 Noether GE. Sample size determination for some common non parametric statistics. J Am Stat Assoc 1987;82:645-7.

22 Koch GG, Tangen CM, Jung JW, et al. Issues for covariance analysis of dichotomous and ordered categorical data from randomized clinical trials and non-parametric strategies for addressing them. Stat Med 1998;17:1863-92.

23 Dekker JHM, Wagenaar RC, Lankhorst GJ, et al. The painful hemiplegic shoulder. Effects of intra-articular triamcinolone acetonide. Am J Phys Med Rehabil 1997;76:43-8. 